\title{
A biotechnological system of root crops preparation for farm animals
}

\author{
Aleksey Brusenkov ${ }^{1, *}$, Vasiliy Kapustin ${ }^{1}$, Vladimir Nemtinov $^{1}$, and Yulia Nemtinova ${ }^{1,2}$ \\ ${ }^{1}$ Tambov State Technical University, 392000, Sovetskaya st., 106, Tambov, Russia \\ ${ }^{2}$ Tambov State Tambov State University named after G.R. Derzhavin, 392000, Internatsionalnaya st., \\ 33, Tambov, Russia
}

\begin{abstract}
It is known that the modern approach to studying complex, multidimensional and interrelated physical or biochemical systems is using system analysis with mathematical modeling methods for describing quantitative laws at all levels of hierarchy. Preliminary analysis has shown that a livestock breeding complex as a whole or any separate technological process can be considered as a multi-level system. In this case, a more complex system is determined not by a larger number of its elements, but by complexity of their properties and relationships at different stages (or levels) of the hierarchical structure. It was determined, that the developed approach to analyzing technological lines for delivery and preparation of root crops allows to consider and solve not only the problem of optimal functioning of the system in producing target products from technical and economic standpoints, but also to establish rational links of the system with the external environment, that is, to assess its environmental efficiency. Therefore, this task becomes the most relevant in developing new technologies and structural schemes aimed at creating low-waste or nonwaste production lines with the maximum use of raw materials and energy resources within the system.
\end{abstract}

\section{Introduction}

The choice of methods and means of cattle feeding depends on many factors such as breed, age, way of livestock keeping, milk yield, forage availability and mechanization level. For example, an increase in milk yields should affect the quantity and quality of feeding diet. The level of processes mechanization allows increasing productivity of forage machines, keeping the feeding regime, reducing animals stress, labor costs and labor intensity of the processes [1].

If technologies of forage preparation and its distribution are considered separately from each other not taking into account quantity and quality of received milk, it is impossible to create energy-saving environmentally safe systems [2 - 5].

Currently, through the study of modern chemical and technological systems, biotechnology in microbiology, genetic and cell engineering and other fields of science an

\footnotetext{
*Corresponding author: nemtinov@mail.gaps.tstu.ru
} 
academic Yu.A.Ovchinnikov has given a definition of biotechnology: "The technology in the broad sense is any use of biological processes for production of target products" [2].

In our case, in order to obtain target livestock products (meat, milk), the system involves such biological objects as animals, humans, root crops and technical means ensuring full implementation of all technological processes in accordance with specified agrotechnical and zootechnical requirements.

Analysis of literary sources on milk production, animals keeping and forage preparation allowed to build up a diagram of a biotechnological system (BTS) for forage preparation including root crops, cleaned and cut in accordance with zootechnical requirements.

Under a biotechnological system we mean a set of devices connected by material, energy and information flows, which perform a certain sequence of operations aimed at obtaining the final product [3 - 9].

\section{Procedure for analyzing engineering solutions for complex systems}

Using heuristic research methods a biotechnological system (BTS) of harvesting, transportation, storage, washing, grinding, dosing, mixing and distribution of root crops for production of animal feed can be represented as a verbal image (figure 1), [9 - 12].

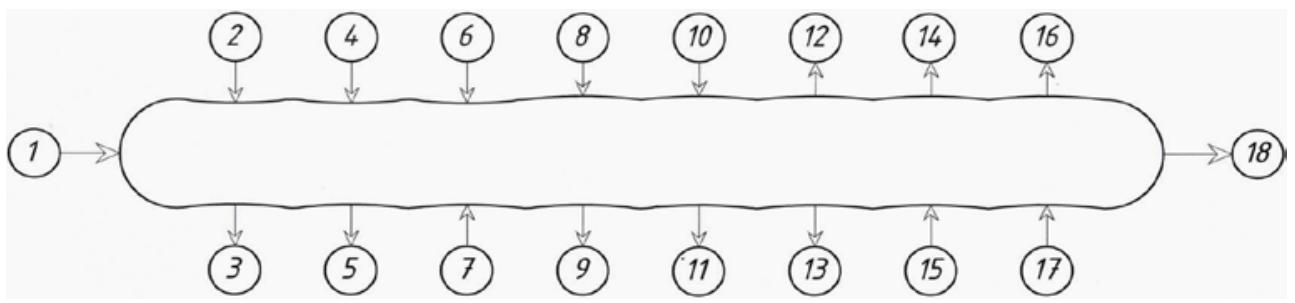

Fig. 1. Verbal image of harvesting, transportation, washing, grinding, mixing, dosing and distribution of forage: 1 - root crops harvesting; 2 - mechanical movement; 3, 5, 9, 11 - separation of impurities; 4,8 - loading of root crops into vehicles; 6 - transportation to places of storage or clamp storing; 7 storage of korneklubneplod; 10 - transportation of root crops to the preparation line; 12 - grinding of root crops; 13 - resizing of root crops; 14 - dosing; 15, 17 - transportation of korneklubneplod; 16 mixing; 18 - distribution of forage to animals.

Mass harvesting of root crops usually begin with the onset of their technical ripeness, when the growth of plants is finished and the yield reaches a maximum. Technical ripeness of root crops is determined in laboratories and on separate plantations (fields) it occurs at different time periods and depends on many factors: soil and climatic conditions, varieties and agrotechnical means used in their cultivation.

Harvesting of root crops is done by harvesting machines which retrieve them from the rows, place onto a conveyor (auger, raddle chain or rotary cleaner), where, together with transporting, impurities (soil, stones, tops and others) are removed from the heap. Actual dirtiness of root crops after harvesting can reach $12 \ldots 20 \%$ by weight or more, depending on the type of soil.

Loading of roots into tractor trailers is done by a raddle chain or a beetloader, which significantly reduce overall dirtiness of root crops (by $3 . .5 \%$ from the initial level) from impurities entering the forage line from clamps or storages, and contributes to improved operation of washers-grinders.

Loaded root crops are transported to clamps or storages. Root crops can be stored in temporary (clamps, piles, trenches) or stationary storages (specialized storages for root 
crops, cellars and others) with active aeration. However, during root crops unloading on the soil (the place of storage clamp) and subsequent uploading into vehicles, dirtiness increases to $5 \%$. Delay in root crops harvesting also adversely affects their quality during long-term storage. The main factors affecting shelf-life of root crops are temperature and humidity. Optimum humidity for storage of root-club products is $90 \ldots 95 \%$. When stored in clamps, humidity usually increases due to release of moisture during root crops respiration. At the same time, there is a loss of their mass - a natural decrease of $5 \ldots 8 \%$ of the total weight of loaded root crops, which occurs in clamps during the storage period from September to May. All these factors affect energy intensity of the process, that is, the cutting force of grinding. The intensity of moisture evaporation depends on variety of root crops, their ripeness, harvesting time, methods of transportation and storage, storage mode[13 -15].

Loading of root crops from storages or clamps to vehicles is carried out by a grab loader, resulting in additional separation of impurities from root crops by $1 . .3 \%$.

Then they are delivered to a technological line of preparation, unloaded into a receiving hopper, from which a conveyor transports them to a washer-grinder. There root crops are completely washed of impurities with clean running water (water flow increases) and fed into the grinder, where they reduce in sizes in accordance with zootechnical requirements. The grinded mass is discharged into a hopper-dispenser or a distributor-mixer with an electronic weighing system. Dosing is crucial for the most accurate forage mix, and mixing - for control of concentration of each individual component in the mixture. Next stage is distribution of ready-made forage to animals.

All BTS processes are directly related to the environment (temperature, humidity) through production of finished products (grinded root crops) for its intended use (animal feeding).

A verbal image of BTS allows visualizing the phenomena occurring in individual elements of the system, its modification, factors affecting individual elements and the system as a whole, taking into account its interaction with the environment.

The purpose of BTS developing is the ability of using and applying system analysis in determining the phenomena occurring in it. The BTS, which includes a set of technological processes, ranging from root crops harvesting and ending with obtaining a product ready for use in animal feeding, with devices, machines and equipment that ensure their functioning, is considered for the first time.

In accordance with system approach to analysis processes of complex BTSs, starting from harvesting and ending with distribution of root crops to animals, the first stage of structural analysis requires development of a hierarchical system that reflects the relationships between individual levels in the system [16 - 17]. This approach helps to identify the main stages of the BTS study, to establish a sequence of interactions between them and organically compare theoretical and experimental data obtained in analysis of each level of the system.

Figure 2 shows a hierarchical scheme of harvesting, transportation and preparation of root crops for feeding, including seven main stages.

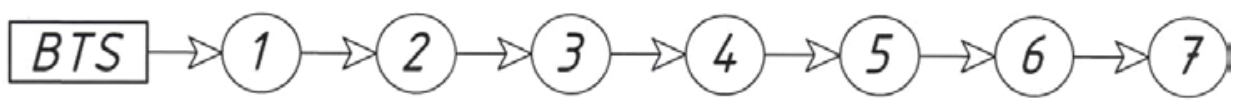

Fig. 2. Hierarchical scheme of harvesting, transportation and preparation of root crops for animals feeding: 1 - root crops harvesting; 2, 4 - transportation 3 - root crops storage; 5 - washing and grinding; 6 - dosing and mixing; 7 - delivery of prepared forage.

The first stage is root crops harvesting, the second - transportation to the place of storage, the third - storage, the fourth - transportation to the place of preparation for 
feeding, the fifth - washing and grinding, the sixth - dosing and, if necessary, mixing with other feeds, the seventh - distribution to animals.

At the first stage, harvesting, root crops are dug out by a beet harvester and go through preliminary cleaning from soil impurities. The model is formalized as digging, cleaning and loading of root crops into a vehicle (figure 3).

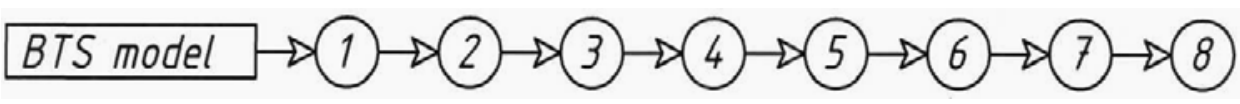

Fig. 3. Block diagram of the BTS's mathematical model: 1 - model of harvesting and cleaning from mechanical impurities; 2, 4- model of transportation; 3 - model of storage and mass transfer; 5 model of hydrodynamics; 6 - model of grinding; 7, 8- model of mass transfer.

At the second stage, root crops transporting by cars and tractors with trailers is presented by the model for determining productivity and by the number of vehicles.

At the third stage, the storage process is described by the mass transfer model (the process of reducing humidity by ventilation).

At the fourth stage, the process of root crops transportation from temporary or permanent storages to the place of their preparation can be carried out by mobile or stationary transport (conveyor), depending on the distance. Depending on the variant, the process can be described by the model of transportation by a screw or belt conveyor or mobile transport.

The fifth stage of the process is described by the model of hydrodynamics (washing of root crops), the sixth - by the theory of grinding, the seventh (dosing) and the eighth (distribution) stages of the process are described by the model of mass transfer.

Each mathematical model of equations and the BTS as a whole are considered as an aggregate of three stages: semantic (physical description), analytical (description by equations) and computational (decision algorithms).

The formalized structure of the BTS can be represented as:

$$
\Sigma:\{\{\grave{I}\},\{\tilde{O}\}, F\},
$$

where $\Sigma$-BTS; $\{\grave{I}\}$ - set of elements in the system; $\{\tilde{\sigma}\}$ - set of links between the system's elements; $F$ - function (new property) of the system.

A BTS can consist of many elements and groups of elements with different properties (material, energy, information), which means that it can be presented structurally, that is:

$$
\Sigma \Sigma:\{\{\overleftarrow{I}\},\{\tilde{O}\}\}
$$

where $\Sigma \Sigma$ - system's structure; $\{\overleftarrow{I}\}$ - set of groups of system's elements; $\{\tilde{o}\}$ - set of relationships between these groups .Here, $M_{1} \cup M_{2} \cup M_{3} \ldots$ or $\bigcup_{\mathrm{n}=1}^{\infty} M_{\mathrm{n}}$.

A process represents a set of BTS's states corresponding to an ordered continuous or discrete change in some parameter that determines the characteristics (properties) of the system. The process parameters can be time $t$, speed $S$, pressure $P$, temperature $T$ and other physical measures.

If we take the transition rule from the situation with the value of time parameter $t_{0}$ to the situation with the value $t \succ t_{0}$ through all its intermediate continuous and discrete values, the BTS's process can be symbolically recorded as: 


$$
S_{\text {tot }}\left(y\left(t_{0}\right)\right)=y(t), y \in y, t \in T,
$$

where $S_{\text {tot }}$-general view of the BTS's process; $y$-values, describing specific characteristics; $y=y \in Y$-process parameter, set of its values $T$. Here, $S_{1} \cup S_{2} \cup S_{3} \ldots$ or $\bigcup_{\mathrm{n}=1}^{\infty} S_{\mathrm{n}}$.

The general view of the process $S_{\text {tot }}^{\cup}$ with control $U$ from the set of possible controls has the form:

$$
S_{\text {tot }}^{\cup}=\left(y\left(t_{0}\right)=y(t, \bigcup), y \in Y, t \in T, u \in \bigcup,\right.
$$

where $U$ - control value.

Control refers to purposeful intervention in the BTS's process, for example, root crops supplying, mixing, dosing and others.

Based on analysis of existing technologies for delivery and preparation of root crops, the main purpose of the BTS when receiving ready-to-use products is reduction in energy and labor costs, harmful effects on the environment, improvement of working conditions for the staff on the basis of solving the problem of finding mathematical dependencies of system's state characteristics (the value of output parameters) and parameters and characteristics of its elements (subsystems) depending on the structure of technological relationships between BTS elements (subsystems).

Due to complexity and presence of various devices, setting the general objective of the BTS requires:

(a) formulation of the overall objective of BTS elements and groups of elements;

b) targeted intervention in the BTS functioning.

If moments $t_{\tilde{\mathrm{n}}}$ exist (if they are specified), characteristics $y_{\tilde{\mathrm{n}}}$ allow achieving the goal $f_{\tilde{\mathrm{n}}}$. Let the state $y_{\tilde{\mathrm{n}}}$ be achieved by the process $S_{\text {tot }}$. Then control $\bigcup_{\tilde{n}}$, allowing to accomplish the goal $f_{\tilde{\mathrm{n}}}$, is defined as a part of $f_{\tilde{\mathrm{n}}}, y_{\tilde{\mathrm{n}}}, \bigcup_{\tilde{\mathrm{n}}}$, satisfying the relations:

$$
S_{\text {tot }}^{\cup}=\left(y\left(t_{0}\right)=y(t, \bigcup), f(y)=f_{\mathrm{c}}, y \in Y, t \in T, u \in \bigcup\right.
$$

The hierarchical structure of the goals in the system will take the form:

$$
G^{0} \rightarrow\left\{G^{\prime}\right\} \rightarrow\left\{G^{\prime \prime}\right\} \rightarrow \ldots
$$

where $G^{0}$ - an overall goal of the BTS; $\left\{G^{\prime}\right\}$ - set of goals of the first hierarchical level; $\left\{G^{\prime \prime}\right\}$ - set of goals of the second hierarchical level.

The tuple recording of the BTS mathematical model can be represented as:

$$
\Sigma:\left\{\tilde{o}^{+}, \tilde{o}^{-}, \grave{a}, t, y, S, V, \bar{V}\right\}, \tilde{o}^{+} \in X, a \in A, t \in T, y \in Y
$$

or:

$$
Z(t)=H\left(\xi_{\mathrm{t}}, z(\xi), x_{\xi t}\right),
$$

where $\tilde{o}^{+}-$set of input actions in the system; $\tilde{\sigma}^{-}-$set of output actions in the system; $\grave{a}-$ constant parameters which characterize the system; $y$-set of parameters which 
characterize the properties of the system; $t$-process parameter in the system; $S$-function, operator that defines system parameters of the process $\grave{a}$ and $t ; V$ - function, operator that defines system inputs parameters $\tilde{o}^{+} ; \tilde{o}^{-}-$function, operator that determines output characteristics of the system by the inputs $\tilde{o}^{+}$with parameters $\grave{a}$ and $t ; \hat{I}$ - operator that establishes a one-to-one dependence from the pair $Z\left(\left(\xi_{\mathrm{t}}\right), x_{\xi t}\right)$, which is specified on the interval

$\xi t$ and called the transition operator.

Equation $Z(t)=H\left(\xi_{\mathrm{t}}, z(\xi), x_{\xi t}\right)$ it is called the equation of state, which determines the final state of the system for a given initial state $Z(\xi)$ and a fragment of the input process $\tilde{O}_{\xi t}$.

A biotechnological system which includes a person, a machine, and a product cannot be considered in isolation from the ecological environment. Systemic unity of machinery, technology, human, animal and habitat are closely interrelated and interdependent in agricultural production. Violation of this unity in any element of the system leads to adverse deviations in the production process and the environment [18 - 20].

Low efficiency of production is often associated with imbalances in the level of development of individual components of the system, as well as with discrepancies between system parameters and natural working conditions of a farm. Division of a complex system into constituent elements, their consideration outside and in connection with the system, allows identifying these imbalances and inconsistencies, establishing the relationship between the characteristics of the system and the final results.

The equation of functional relations between BTS's elements in general is implicit functions of many variables:

$$
F_{\mathrm{i}}=\left(\ddot{I}_{\mathrm{i}}, \eta, v, K, \ddot{A}\right),
$$

where $\ddot{I}_{\mathrm{i}}$ - state parameters of physical flows; $\eta$-efficiency of BTS's elements; $v$-physical and chemical constants; $K$-structural and technological parameters of BTS; $\ddot{A}$ - parameters of technological modes.

Thus, system approach aims on integrated studying of BTSs in a complex way, making decisions taking into account all significant technological, technical and environmental factors and their interdependencies.

\section{Results and discussion}

The authors have revealed that a large number of factors affecting the efficiency of technological processes of livestock products manufacturing, their complex nature, differences in evaluation criteria and complex relationships make it necessary to implement system approach to their production. It was shown that the set of ordered and interacting interdependent elements can be represented in the form of a hierarchical structure, and system approach and system analysis should be used for their study. System analysis is currently the main method of scientific study of complex systems, which includes a set of processes and phenomena of different nature. The problems of mathematical modeling and optimization of individual devices and subsystems of technological schemes, and the system as a whole, are solved from the standpoint of system analysis. At the same time, the methodology of system approach is also applied to analyzing hierarchical levels of the system. When considering any production from the standpoint of system analysis, it is 
possible to identify a number of elements, each of which in turn can be considered as a biotechnological system. Each of these elements (subsystems) is characterized by a complex hierarchical structure of relations, which are also subjected to system approach.

\section{Conclusion}

A distinctive feature of this work is that a biotechnological system that consists of the set of technological processes, ranging from preparation of feed rations, including washing and grinding of root crops, to production of final products with the help of machines and equipment, is considered for the first time. This was done by solving the problem of decomposition of the BTS into subsystems and individual elements with their subsequent quantitative analysis based on mathematical models and the problem of synthesis of an optimal BTS based on the generalized efficiency criterion. Therefore, the proposed principles of BTS modeling for preparation of root crops for cattle feeding, will serve as the basis for practical improvement and increasing their efficiency.

\section{References}

1. V. Khmelovskyi, S. Rogach, O. Tonkha, Y. Rosamaha. Quality evaluation of mixing fodder by mobile combined units, Engineering for Rural Development 18. 299-304. (2019)

2. V.V. Kafarov, Yu. Naletov, Yu.A. Chernegov. Organization of technological systems with hierarchical structure, Doklady Chemical technology. 301(3). 87-90 (2019)

3. S.A. Salami, G. Luciano, M.N. O'Grady, J.P. Kerry, A. Priolo. Sustainability of feeding plant by-products: A review of the implications for ruminant meat production. Animal Feed Science and Technology. 251. 37-55 (2019)

4. O.G. Vysotskiy, A.I. Grishenkov, A.M. Khlopyanikov, G.V. Khlopyanikova, A.M. Lobanovsky. Efficiency and environmental safety of innovative biotechnological production systems in agriculture, Journal of Advanced Research in Dynamical and Control Systems. 11(2). 412-418 (2019)

5. L. Lalaleo, R. Alcazar, J. Palazon, E. Moyano, R.M. Cusido, M. Bonfill Comparing aryltetralin lignan accumulation patterns in four biotechnological systems of Linum album, Journal of Plant Physiology. 228. 197-207 (2018)

6. D. Hidalgo, V. Steinmetz, M. Brossat, L. Tournier-Couturier, R.M. Cusido, P. Corchete, J. Palazon. An optimized biotechnological system for the production of centellosides based on elicitation and bioconversion of Centella asiatica cell cultures, Engineering in Life Sciences. 17(4). 413-419 (2017)

7. K.K.S.A. Albuquerque, W.W.C. Albuquerque, R.M.P.B. Costa, J.M.S. Batista, D.A.V. Marques, R.P. Bezerra, P.N. Herculano, A.L.F Porto. Biotechnological potential of a novel tannase-acyl hydrolase from Aspergillus sydowii using waste coir residue: Aqueous two-phase system and chromatographic techniques, Biocatalysis and Agricultural Biotechnology. 23(1). 101453 (2020)

8. A. Apazhev, V. Smelik, Y. Shekikhachev, L. Hazhmetov, Combined unit for preparation of soil for sowing grain crops, Engineering for Rural Development. 18. 192-198 (2019)

9. P.Oleinik, N. Cherednichenko, Organization of demolition works during production buildings reconstruction, IOP Conference Series: Earth and Environmental Science. 403(1). 012189 (2019)

10. I. Vorotnikov, M. Gutuev, K. Petrov, O. Esin. Concept of regional technical service development, Espacios. 38(23) 22 (2017) 
11. V.A. Nemtinov, A.N. Zazulya, V.P. Kapustin, Yu.V. Nemtinov. Analysis of decisionmaking options in complex technical system design, Journal of Physics: Conf. Series. 1278(1). 012018 (2019)

12. D.E. Houssaini, S. Khriji,K. Besbes, O. Kanoun. Wireless sensor networks in agricultural applications, Energy Harvesting for Wireless Sensor Networks: Technology, Components and System Design. 323-342 (2018)

13. V.A. Nemtinov, Y.V. Nemtinova, An approach to regulating the relationships between environmental users, Journal of Computer and Systems Sciences International. 43(5). 800-804 (2004)

14. O.V. Myalo, S.P. Prokopov, V.V. Myalo, A.S. Soyunov, E.V. Demchuk. Material and technical support of the enterprises of the agro-industrial complex of the Omsk region management and certification of the technical component of the production processes in crop production, IOP Conference Series: Materials Science and Engineering. 582(1). 012028 (2019)

15. K. Nemtinov, A. Eruslanov, Y. Nemtinova, V. Nemtinov. Rationale construction of individual elements of technological complex, MATEC Web of Conferences. 224. 02036 (2018)

16. V. Alekseev, D. Lakomov, A. Shishkin, G.Al. Maamari and M. Nasraoui. Simulation images of external objects in a virtual simulator for training human-machine systems operators, Jornal of Physics: Conference Series. 1278. 012032 (2019)

17. O. Krol, V. Sokolov. Modelling of spindle nodes for machining Jornal of Physics: Conference Series. 1084. 012007 (2018)

18. V.A. Nemtinov, Yu.V. Nemtinova. On an approach to designing a decision making system for state environmental examination, Journal of Computer and Systems Sciences International. 44(3). 389-398 (2005)

19. V.G. Mokrozub, V.A. Nemtinov A.V. Mokrozub, Procedural model for designing multiproduct chemical plants, Chemical and Petroleum Engineering. 53(5-6). 326331 (2017)

20. A.B. Borisenko, S.V. Karpushkin. Hierarchy of processing equipment configuration design problems for multiproduct chemical plants, J. of Computer and Systems Sci. Int. 53(3). 410-419 (2004) 